\title{
Confounding factors of non-invasive tests for nonalcoholic fatty liver disease
}

\author{
Janae Wentong Wai ${ }^{1}$ Charmaine $\mathrm{Fu}^{1} \cdot$ Vincent Wai-Sun Wong ${ }^{1,2}$
}

Received: 27 February 2020/Accepted: 27 March 2020/Published online: 25 May 2020

(C) The Author(s) 2020

\begin{abstract}
Nonalcoholic fatty liver disease (NAFLD) affects at least $25 \%$ of the general adult population worldwide. Because only a fraction of the patients would develop liver-related complications, it is preferable to perform non-invasive tests as the initial assessment. This review summarizes the known and potential confounding factors that affect the performance of non-invasive tests of hepatic steatosis and fibrosis in patients with NAFLD. Clinicians may apply the knowledge and exercise caution in selecting investigations and interpreting test results when confounding factors are present.
\end{abstract}

Keywords Nonalcoholic fatty liver disease - Nonalcoholic steatohepatitis - Liver fibrosis - Cirrhosis - Transient elastography

$\begin{array}{ll}\text { Abbreviations } \\ \text { ALT } & \text { Alanine aminotransferase } \\ \text { APRI } & \text { AST-to-platelet ratio index } \\ \text { AST } & \text { Aspartate aminotransferase } \\ \text { CAP } & \text { Controlled attenuation parameter } \\ \text { ELF } & \text { Enhanced liver fibrosis } \\ \text { MRI- } & \text { Magnetic resonance imaging proton density fat } \\ \text { PDFF } & \text { fraction } \\ \text { NAFL } & \text { Nonalcoholic fatty liver } \\ \text { NAFLD } & \text { Nonalcoholic fatty liver disease }\end{array}$

Vincent Wai-Sun Wong

wongv@cuhk.edu.hk

1 Department of Medicine and Therapeutics, The Chinese University of Hong Kong, 9/F, Prince of Wales Hospital, 30-32 Ngan Shing Street, Hong Kong, China

2 State Key Laboratory of Digestive Disease, The Chinese University of Hong Kong, Hong Kong, China

\begin{tabular}{|c|c|}
\hline NASH & Nonalcoholic steatohepatitis \\
\hline PIIINP & Procollagen III amino-terminal peptide \\
\hline Pro-C3 & $\begin{array}{l}\text { Neo-epitope-specific competitive enzyme- } \\
\text { linked immunosorbent assay for PIIINP }\end{array}$ \\
\hline SHIP & Study of health in pomerania \\
\hline TIMP1 & Tissue inhibitor of metalloproteinases 1 \\
\hline
\end{tabular}

\section{Introduction}

Nonalcoholic fatty liver disease (NAFLD) affects at least $25 \%$ of the global adult population $[1,2]$, and has become one of the leading causes of cirrhosis and hepatocellular carcinoma in Western countries [3, 4]. Although NAFLD appears to be milder in Asia [5], the rise in liver decompensation, hepatocellular carcinoma and death due to NAFLD is particularly steep in China [6]. NAFLD is divided into nonalcoholic fatty liver (NAFL, also known as simple steatosis) and nonalcoholic steatohepatitis (NASH) according to disease severity [7]. The latter is characterized by the presence of lobular inflammation and hepatocyte ballooning. While NAFL can progress to NASH and vice versa [8], on the whole, NASH patients are at a higher risk of fibrosis progression and liver-related complications [9, 10]. Accumulating fibrosis eventually results in cirrhosis and subsequent complications. Because fibrosis is the path towards cirrhosis, it comes as no surprise that fibrosis has the strongest correlation with liver-related morbidity and mortality in longitudinal studies [11].

In the past, liver biopsy was the primary investigation to determine the severity of NAFLD. It also serves to exclude other liver diseases. However, it is an invasive procedure with a $0.3 \%$ risk of bleeding. Patient acceptability is low, 
and it is undesirable to perform liver biopsy repeatedly to assess disease progression and treatment response. More importantly, liver biopsy is not a real gold standard for the evaluation of the histological features of NAFLD. Because a liver biopsy sample only represents around 1/50,000 of the entire liver volume, there is considerable sampling variability [12]. The interpretation of individual histological features of NAFLD also suffers from intraobserver and interobserver variability [13]. Among the key histological features of NAFLD, the reproducibility and interobserver concordance are particularly poor for lobular inflammation and hepatocyte ballooning, which are both defining features of NASH. There has therefore been much interest in the development of non-invasive tests to replace or supplement liver biopsy in the past 2 decades.

Non-invasive tests of NAFLD can be classified by the target disease state or the type of test. Disease states of interest include the detection of hepatic steatosis (for the diagnosis of NAFLD or using steatosis improvement as treatment outcomes in early phase studies), NASH, and fibrosis. Types of tests include simple scores based on routine clinical and laboratory parameters, specific blood biomarkers, and imaging techniques. There have already been numerous reviews on non-invasive tests $[14,15]$. This review focuses instead on confounding factors that affect the performance and accuracy of non-invasive tests in NAFLD. In addition, because biomarkers for NASH are less well developed and few studies have examined the confounding factors of such biomarkers, this article restricts the discussion to non-invasive tests of hepatic steatosis and fibrosis. As far as possible, we discuss confounding factors identified in original studies. For non-invasive tests without a clear analysis of confounding factors, we also discuss potential confounding factors based on the components or mechanisms of those tests.

\section{Non-invasive tests of hepatic steatosis}

Hepatic steatosis is the defining feature of NAFLD. Current guidelines define NAFLD as the presence of $\geq 5 \%$ hepatic steatosis by histology in the absence of excess alcohol consumption [7, 16, 17]. The clinical significance of the degree of hepatic steatosis is unclear. In longitudinal studies, histological steatosis grade and controlled attenuation parameter measurement by vibration-controlled transient elastography had no or weak association with overall and liver-related mortality [18-20]. In contrast, several studies suggest that an improvement in magnetic resonance imaging proton density fat fraction (MRI-PDFF) correlate with histological improvement, defined as an improvement in the NAFLD activity score or resolution of
NASH [21-23], though others have not observed such correlation $[24,25]$.

\section{Simple scores for hepatic steatosis}

Simple scores for hepatic steatosis are typically derived by logistic regression or other statistical methods using clinical or laboratory factors that are associated with the presence of hepatic steatosis. The Fatty Liver Index, United States Fatty Liver Index and the Study of Health in Pomerania (SHIP) score, for example, were derived using abdominal ultrasonography as the reference standard [26-28]. Other scores used more accurate measurements of hepatic steatosis as reference standards. For instance, SteatoTest was derived using artificial intelligence against liver histology of patients with different liver diseases as the reference standard [29]. The NAFLD ridge score [30] and the Dallas Steatosis Index [31] were derived using proton-magnetic resonance spectroscopy or MRI-PDFF as the reference standard. The latter has the advantage of reflecting the general population or primary care setting, where these scores would be most applicable.

Because these scores include common clinical and laboratory parameters, they can be calculated with almost no additional costs. However, the parameters are statistical associations and do not directly measure hepatic steatosis; thus, they are also subject to the influence of confounding factors (Table 1). In particular, lipids (triglycerides and/or cholesterol in Fatty Liver Index, SteatoTest, SHIP score, NAFLD ridge score and Dallas Steatosis Index) and glycemic parameters (glucose, hemoglobin $\mathrm{A}_{1 \mathrm{c}}$ and/or insulin in the United States Fatty Liver Index, NAFLD liver fat score, SteatoTest, NAFLD ridge score and Dallas Steatosis Index) are affected by drug treatments. Patients receiving treatment for dyslipidemia and diabetes may have a dissociation between improvements in simple scores and improvements in hepatic steatosis. The capacity of indices to reflect longitudinal changes in intrahepatic lipid following lifestyle intervention is also diet dependent, and can be monitored with moderate precision in low-fat diets but not in low-carbohydrate diets [32]. A low fat diet alters body weight, waist circumference, triacylglycerol, and gamma-glutamyl transpeptidase, and this is reflected by changes in NAFLD-Liver Fat Score and Fatty Liver Index. However, a low-carbohydrate diet appears to affect liver metabolism and insulin sensitivity differently and changes in intrahepatic fat does not result in changes in liver fat scores. The performance of these fatty liver scores in patients receiving metabolic treatment and lifestyle modifications should be clarified in future studies.

On the other hand, other than exceptional circumstances (e.g. profound weight reduction after bariatric surgery), remission of metabolic diseases is rare. A diabetic patient 
Table 1 Simple scores of hepatic steatosis and potential confounding factors

\begin{tabular}{|c|c|c|c|}
\hline Score & Components & Test performance & Potential confounding factors \\
\hline Fatty liver index & BMI, waist circumference, triglycerides, GGT & $\begin{array}{l}\text { AUROC } 0.84, \text { Sn } \\
87 \%, \text { Sp } 64 \%\end{array}$ & $\begin{array}{l}\text { Triglycerides affected by lipid- } \\
\text { lowering treatment } \\
\text { GGT affected by alcohol } \\
\text { consumption }\end{array}$ \\
\hline $\begin{array}{l}\text { United States } \\
\text { fatty liver } \\
\text { index }\end{array}$ & Age, waist circumference, insulin, glucose, GGT, ethnicity & $\begin{array}{l}\text { AUROC } 0.80, \mathrm{Sn} \\
86 \%, \mathrm{Sp} 88 \%\end{array}$ & $\begin{array}{l}\text { Insulin and glucose affected by } \\
\text { diabetic treatment } \\
\text { GGT affected by alcohol } \\
\text { consumption }\end{array}$ \\
\hline $\begin{array}{l}\text { Hepatic } \\
\text { steatosis } \\
\text { index }\end{array}$ & AST/ALT ratio, BMI, sex, diabetes & $\begin{array}{l}\text { AUROC } 0.81, \text { Sn } \\
93 \%, \text { Sp } 92 \%\end{array}$ & \\
\hline $\begin{array}{l}\text { NAFLD liver } \\
\text { fat score }\end{array}$ & Metabolic syndrome, diabetes, insulin, AST, ALT & $\begin{array}{l}\text { AUROC } 0.86, \mathrm{Sn} \\
86 \%, \mathrm{Sp} 71 \%\end{array}$ & $\begin{array}{l}\text { Insulin affected by diabetic } \\
\text { treatment }\end{array}$ \\
\hline SteatoTest & $\begin{array}{l}\text { Components of FibroTest-ActiTest (GGT, total bilirubin, alpha-2- } \\
\text { macroglobulin, apolipoprotein A1, haptoglobin, ALT) plus } \\
\text { BMI, cholesterol, triglycerides, glucose, age, sex }\end{array}$ & $\begin{array}{l}\text { AUROC 0.79, Sn } \\
\text { 85-100\%, Sp } \\
83-100 \%\end{array}$ & $\begin{array}{l}\text { Haptoglobin affected by } \\
\text { hemolysis } \\
\text { Bilirubin affected by hemolysis, } \\
\text { biliary pathology and Gilbert } \\
\text { syndrome } \\
\text { GGT affected by alcohol } \\
\text { consumption } \\
\text { Cholesterol and triglycerides } \\
\text { affected by lipid-lowering } \\
\text { treatment } \\
\text { Glucose affected by diabetic } \\
\text { treatment }\end{array}$ \\
\hline $\begin{array}{l}\text { Study of health } \\
\text { in pomerania } \\
\text { score }\end{array}$ & $\begin{array}{l}\text { Age, AST, ALT, waist circumference, ferritin, BMI, triglycerides, } \\
\text { gout }\end{array}$ & AUROC 0.88 & $\begin{array}{l}\text { Triglycerides affected by lipid- } \\
\text { lowering treatment } \\
\text { Ferritin is an acute phase protein }\end{array}$ \\
\hline $\begin{array}{l}\text { NAFLD ridge } \\
\text { score }\end{array}$ & $\begin{array}{l}\text { ALT, HDL-cholesterol, triglycerides, hemoglobin } A_{1 c} \text {, white blood } \\
\text { cell count, hypertension }\end{array}$ & $\begin{array}{l}\text { AUROC } 0.87, \text { Sn } \\
92 \%, \text { Sp } 90 \%\end{array}$ & $\begin{array}{l}\text { HDL-cholesterol and triglycerides } \\
\text { affected by lipid-lowering } \\
\text { treatment } \\
\text { Hemoglobin } \mathrm{A}_{1 \mathrm{c}} \text { affected by } \\
\text { diabetic treatment } \\
\text { White cell count affected by } \\
\text { infection or inflammation }\end{array}$ \\
\hline $\begin{array}{l}\text { Dallas steatosis } \\
\text { index }\end{array}$ & $\begin{array}{l}\text { ALT, BMI, age, sex, triglycerides, glucose, diabetes, hypertension, } \\
\text { ethnicity }\end{array}$ & $\begin{array}{l}\text { AUROC } 0.82, \text { Sn } \\
86 \%, \text { Sp } 90 \%\end{array}$ & $\begin{array}{l}\text { Triglycerides affected by lipid } \\
\text { lowering treatment } \\
\text { Glucose affected by diabetic } \\
\text { treatment }\end{array}$ \\
\hline
\end{tabular}

$A L T$ alanine aminotransferase, $A S T$ aspartate aminotransferase, $A U R O C$ area under the receiver-operating characteristics curve, $B M I$ body mass index, $G G T$ gamma-glutamyl transpeptidase, $H D L$ high-density lipoprotein, $N A F L D$ nonalcoholic fatty liver disease, $S n$ sensitivity, $S p$ specificity

would continue to be considered to have diabetes mellitus even if she manages to lose weight and reduce the dosage of anti-diabetic drugs. The scores do not take the severity of disease into account. As a result, scores including metabolic diagnoses (e.g. diabetes in Hepatic Steatosis Index, NAFLD liver fat score and Dallas Steatosis Index; metabolic syndrome in NAFLD liver fat score; and hypertension in the NAFLD ridge score and Dallas Steatosis Index) may be less suitable for the detection of improvement in hepatic steatosis over time. This phenomenon also applies to other irreversible factors such as age, sex and ethnicity.

Gamma-glutamyl transpeptidase (in the Fatty Liver Index, United States Fatty Liver Index and SteatoTest) is increased with alcohol consumption [33]. Although the diagnosis of NAFLD requires exclusion of excess alcohol consumption, the distinction between NAFLD and alcoholrelated liver disease is arbitrary and mainly for research purposes. In real life, many patients have fatty liver due to both metabolic factors and alcohol, and such patients often 
have more severe disease and worse outcomes [34]. The performance of these simple scores in patients with and without alcohol consumption is thus of practical importance and should be clarified in future studies.

In addition, haptoglobin (in SteatoTest) is affected by hemolysis. The total bilirubin (in SteatoTest) is increased in patients with hemolysis, biliary pathology and Gilbert syndrome. White cell count (in the NAFLD ridge score) is affected by infection and hematological diseases. Ferritin (in the SHIP score) is an acute phase protein and is increased in inflammatory states.

\section{Imaging studies}

\section{Routine imaging studies}

In routine clinical setting, abdominal ultrasonography is primarily used to diagnose fatty liver (Table 2). Although it is inexpensive and widely available, ultrasonography is operator dependent. It is important to report the criteria to diagnose NAFLD and the interobserver concordance in clinical research using ultrasonography. Alternatively, some studies used stored ultrasound images to define NAFLD or validate the performance of operators [35]. While ultrasonography has good accuracy to diagnose fatty liver when hepatic steatosis exceeds $30 \%$, it is less sensitive to mild steatosis [36]. Besides, ultrasonography does not perform well in patients with morbid obesity because of poor image quality. A high riding liver and focal fatty sparing also affect the interpretation of ultrasound images.

In a study of 171 patients with various causes of hepatitis from Taiwan, age, body mass index and fibrosis stage were independent factors associated with discordance between ultrasonography and liver histology in the detection of hepatic steatosis [37], but the confounding effect of age was not observed in other studies [38]. Theoretically, aging is associated with renal decline and changes in echotexture. Because one of the key features of fatty liver on ultrasonography is bright liver echotexture in relation to the kidney, aging may affect this comparison. Likewise, the liver echotexture is affected by advanced fibrosis and cirrhosis, which in turn may influence the diagnosis of fatty liver.

The attenuation values of computed tomography have inverse correlation with the degree of hepatic steatosis [39, 40]. Hepatic iron overload increases liver attenuation and may affect the determination of hepatic steatosis [41]. Because of radiation exposure, computed tomography is not primarily used for the detection of NAFLD.

\section{Controlled attenuation parameter}

The amplitude of ultrasound waves decreases more rapidly in a steatotic liver. This explains why deeper tissues are less clear when one uses ultrasonography to examine a patient with NAFLD. Controlled attenuation parameter (CAP) by vibration-controlled transient elastography makes use of this physical phenomenon to measure the attenuation of ultrasound waves and thereby estimates the severity of hepatic steatosis. Overall, CAP has moderate accuracy in detecting fatty liver, but there is considerable overlap of CAP values among steatosis grades [42]. Nevertheless, a recent study showed that CAP was reduced in a dose-response fashion during acetyl Co-A carboxylase inhibitor treatment for NAFLD [43]. Because vibrationcontrolled transient elastography is a point-of-care test, its role as a monitoring tool during NASH treatment deserves further evaluation.

Similar to ultrasonography, CAP is affected by obesity. Above all, failed examinations are more common in obese patients [44], though this problem is largely mitigated by the development of the XL probe [45]. Studies from Malaysia and Japan suggest that the accuracy of CAP for the detection of hepatic steatosis was also lower in obese

Table 2 Imaging studies of hepatic steatosis and potential confounding factors

\begin{tabular}{|c|c|}
\hline Test & Potential confounding factors \\
\hline Abdominal ultrasonography & $\begin{array}{l}\text { Difficult examination in obese patients and patients with high riding liver } \\
\text { and focal fatty sparing } \\
\text { Accuracy may be lower in older patients and patients with significant liver } \\
\text { fibrosis } \\
\text { Operator experience }\end{array}$ \\
\hline Computed tomography & Hepatic iron content may affect liver attenuation \\
\hline Controlled attenuation parameter & $\begin{array}{l}\text { Failure rate higher in obese patients } \\
\text { Accuracy may also be lower in obese patients }\end{array}$ \\
\hline $\begin{array}{l}\text { Proton-magnetic resonance spectroscopy or magnetic resonance } \\
\text { imaging proton density fat faction }\end{array}$ & $\begin{array}{l}\text { Hepatic iron content may affect the measurement of hepatic fat fraction, but } \\
\text { this can be corrected during analysis }\end{array}$ \\
\hline
\end{tabular}


patients [46, 47]. Moreover, significant liver fibrosis may affect ultrasound attenuation and lower the diagnostic performance of CAP [47].

Although food intake and active hepatitis are wellknown causes of false positive liver stiffness measurement, these factors do not appear to affect CAP [48, 49]. With that said, because CAP and liver stiffness are measured simultaneously during vibration-controlled transient elastography examination, clinicians should still ask patients to fast before examination and refrain from performing vibration-controlled transient elastography in patients with risk factors of false positive results (see below).

Studies from Europe, the United States and Asia suggest that the interquartile range of CAP can serve as reliability criteria of CAP. If the interquartile range exceeds $30-40 \mathrm{~dB} / \mathrm{m}$, the accuracy of CAP measurements may be reduced [50-52]. Although another multicenter study from the United Kingdom suggests otherwise, that study only included patients suspected to have NAFLD and did not have a sufficient number of controls for comparison [53].

\section{Magnetic resonance imaging}

Proton-magnetic resonance spectroscopy and MRI-PDFF are highly reproducible and accurate and can be considered as the gold standard to quantify hepatic steatosis. Because the two techniques have almost identical accuracy and MRI-PDFF examines the entire liver and does not require additional sequences, the former is not the preferred MRIbased technique [54]. Although iron deposition may affect the estimation of steatosis, the overall effect is mild and can be corrected during analysis [55].

\section{Non-invasive tests of hepatic fibrosis}

Fibrosis is undoubtedly the histological feature with the strongest correlation with liver-related morbidity and mortality $[19,56]$. Portal hypertension and cirrhotic complications only develop in patients with cirrhosis $[13,57,58]$. Although hepatocellular carcinoma has been well reported in non-cirrhotic patients with NAFLD [59], cirrhosis remains one of the most important risk factors for hepatocellular carcinoma [60, 61], and the absolute incidence of hepatocellular carcinoma in the non-cirrhotic population is very low [62]. Thus, the diagnosis of fibrosis and cirrhosis in patients with NAFLD has major prognostic implications and is pivotal in selecting patients for hepatocellular carcinoma and varices surveillance.

Furthermore, because of the close association between fibrosis and clinical outcomes, regulators such as the United States Food and Drug Administration and the European Medicines Agency recognize histological fibrosis improvement with no worsening of NASH as one of the key endpoints for conditional drug approval in phase 3 NASH trials [63].

\section{Simple fibrosis scores}

Similar to simple scores for hepatic steatosis described above, fibrosis scores were derived and validated by statistical methods using factors that were independently associated with fibrosis (Table 3). With few exceptions, liver biopsy was the reference standard for those scores. For historical reasons, most of the scores were initially tested in patients with chronic hepatitis $\mathrm{C}$ and subsequently validated in patients with NAFLD. Although the diagnostic accuracy is modest, these scores are inexpensive and can be performed easily at primary care setting. In one study from the United Kingdom, a referral pathway based on the use of Fibrosis-4 index followed by the Enhanced Liver Fibrosis panel increased the identification of patients with advanced fibrosis or cirrhosis by four-fold [64]. Although none of these scores is good enough to rule in advanced fibrosis, they all have respectable negative predictive values to exclude advanced fibrosis, particularly at the community level or primary care setting [65, 66]. Importantly, several studies have confirmed their roles in excluding future development of liver-related morbidity and mortality $[67,68]$. Therefore, it is reasonable to apply these scores in primary care settings. Patients with low fibrosis scores can be safely monitored.

Few studies specifically looked at reasons for inaccurate prediction by fibrosis scores. In a multicenter European study of 634 patients with biopsy-proven NAFLD, the aspartate aminotransferase (AST)-to-alanine aminotransferase (ALT) ratio, NAFLD fibrosis score and Fibrosis-4 index performed poorly for the diagnosis of advanced fibrosis in those aged 35 years or below [69]. In the same study, the specificity of the Fibrosis-4 index and NAFLD fibrosis score decreased to unacceptable levels in patients aged 65 years or above. This is because age is a component of these two fibrosis scores [70, 71]. On the other hand, Fibrosis-4 index and NAFLD activity score do not appear to be affected by body mass index or ALT level $[72,73]$. In contrast, in our experience, AST is often higher than ALT in normal individuals with normal ALT level (unpublished results from our population cohort) [74]. One should exercise caution when interpreting scores with AST/ALT ratio as a component in patients with normal ALT.

Platelet count is a component of the AST-to-platelet ratio index, Fibrosis-4 index and NAFLD fibrosis score because thrombocytopenia is a feature of cirrhosis due to hypersplenism [70, 71, 75]. However, platelets may also decrease in immune thrombocytopenia purpura and bone marrow diseases. On the other hand, platelets may increase 
Table 3 Serum tests of hepatic fibrosis and potential confounding factors

\begin{tabular}{|c|c|c|c|}
\hline Serum tests & Components & Test performance & Potential confounding factors \\
\hline $\begin{array}{l}\mathrm{AST} / \mathrm{ALT} \\
\text { ratio }\end{array}$ & AST, ALT & AUROC $0.66-0.74, \mathrm{Sn} 40 \%, \mathrm{Sp} 80 \%$ for F3 & Poor performance in patients aged $\leq 35$ years \\
\hline $\begin{array}{l}\text { AST-to- } \\
\text { platelet } \\
\text { ratio index } \\
\text { (APRI) }\end{array}$ & AST, platelet & AUROC 0.74, Sn $65 \%$, Sp $72 \%$ for F3 & $\begin{array}{l}\text { Platelets may decrease in immune } \\
\text { thrombocytopenia purpura and bone } \\
\text { marrow diseases } \\
\text { Platelets may increase in blood loss or } \\
\text { myeloproliferative disease }\end{array}$ \\
\hline $\begin{array}{l}\text { Fibrosis-4 } \\
\text { index }\end{array}$ & Age, AST, ALT, platelet & AUROC 0.80, Sn $65 \%$, Sp $97 \%$ for F3 & $\begin{array}{l}\text { Poor performance in patients aged } \leq 35 \text { years } \\
\text { Low specificity in patients aged } \geq 65 \text { years } \\
\text { Platelets may decrease in immune } \\
\text { thrombocytopenia purpura and bone marrow } \\
\text { diseases } \\
\text { Platelets may increase in blood loss or } \\
\text { myeloproliferative disease }\end{array}$ \\
\hline $\begin{array}{l}\text { NAFLD } \\
\text { fibrosis } \\
\text { score }\end{array}$ & $\begin{array}{l}\text { Age, BMI, impaired fasting } \\
\text { glucose or diabetes, AST, } \\
\text { ALT, platelet, albumin }\end{array}$ & $\begin{array}{l}\text { AUROC } 0.75-0.82, \text { Sn } 73-82 \%, \text { Sp } 96-98 \% \\
\text { for F3 }\end{array}$ & $\begin{array}{l}\text { Poor performance in patients aged } \leq 35 \text { years } \\
\text { Low specificity in patients aged } \geq 65 \text { years } \\
\text { Platelets may decrease in immune } \\
\text { thrombocytopenia purpura and bone marrow } \\
\text { diseases } \\
\text { Platelets may increase in blood loss or } \\
\text { myeloproliferative disease } \\
\text { Albumin may decrease in chronic illnesses, } \\
\text { malnutrition, nephrotic syndrome and } \\
\text { protein-losing enteropathy } \\
\text { Ethnicity }\end{array}$ \\
\hline BARD score & AST, ALT, BMI, diabetes & AUROC $0.69-0.81$, Sn $62 \%$, Sp $66 \%$ for F3 & $\begin{array}{l}\text { BARD score appears to be less accurate in } \\
\text { Japanese and Chinese patients, possibly due } \\
\text { to different fat distribution at the same BMI }\end{array}$ \\
\hline $\begin{array}{l}\text { FibroMeter } \\
\text { NAFLD }\end{array}$ & $\begin{array}{l}\text { Body weight, prothrombin } \\
\text { index, ALT, AST, ferritin, } \\
\text { fasting glucose }\end{array}$ & $\begin{array}{l}\text { AUROC } 0.76, \text { Sn } 22 \%, \text { Sp } 97 \% \text { for } \mathrm{F} 2 \\
\text { AUROC } 0.77, \text { Sn } 27 \%, \text { Sp } 95 \% \text { for } \mathrm{F} 3\end{array}$ & $\begin{array}{l}\text { Prothrombin index affected by anti-coagulants } \\
\text { Ferritin is an acute phase protein } \\
\text { Glucose is affected by anti-diabetic treatment }\end{array}$ \\
\hline $\begin{array}{l}\text { Enhanced } \\
\text { liver } \\
\text { fibrosis } \\
\text { panel }\end{array}$ & $\begin{array}{l}\text { PIIINP, hyaluronic acid, } \\
\text { TIMP1 }\end{array}$ & $\begin{array}{l}\text { AUROC } 0.92, \text { Sn } 88 \%, \text { Sp } 81 \% \text { for } \mathrm{F} 1 \text {; } \\
\text { AUROC } 0.98, \text { Sn } 94 \%, \text { Sp } 93 \% \text { for F2; } \\
\text { AUROC } 0.99, \text { Sn } 100 \%, \text { Sp } 98 \% \text { for } \mathrm{F} 3\end{array}$ & $\begin{array}{l}\text { PIIINP is increased in other fibrotic diseases } \\
\text { or bone fracture } \\
\text { TIMP1 is increased in cancer and } \\
\text { inflammation }\end{array}$ \\
\hline FibroTest & $\begin{array}{l}\text { GGT, total bilirubin, alpha-2- } \\
\text { macroglobulin, } \\
\text { apolipoprotein A1, } \\
\text { haptoglobin }\end{array}$ & Non-binary AUROC for fibrosis 0.88 & $\begin{array}{l}\text { Haptoglobin affected by hemolysis } \\
\text { Bilirubin affected by hemolysis, biliary } \\
\text { pathology and Gilbert syndrome } \\
\text { GGT affected by alcohol consumption }\end{array}$ \\
\hline
\end{tabular}

$A L T$ alanine aminotransferase, $A S T$ aspartate aminotransferase, $A U R O C$ area under the receiver-operating characteristics curve, $B M I$ body mass index, GGT gamma-glutamyl transpeptidase, NAFLD nonalcoholic fatty liver disease, PIIINP procollagen III amino-terminal peptide, $S n$ sensitivity, $S p$ specificity, TIMP1 tissue inhibitor of metalloproteinases 1

in myeloproliferative disease or in response to blood loss. It has been reported that the accuracy of non-invasive fibrosis scores in identifying advanced fibrosis may be reduced if the platelet count is greater than $150 \times 10^{9} / \mathrm{L}$ [76]. The NAFLD fibrosis score also includes albumin, as protein synthesis is impaired in patients with advanced liver disease [71]. However, hypoalbuminemia may also develop in other conditions, such as in patients with chronic illnesses, malnutrition, nephrotic syndrome or protein-losing enteropathy.

In addition, the diagnostic accuracy of the non-invasive tests may be altered depending on the ethnicity. It is well known that the severity of NAFLD differs between ethnic groups. South Asians develop more metabolic complications at lower body mass indices, compared to Western populations. A study showed that the accuracy of the 
NAFLD fibrosis score, AST-to-platelet ratio index (APRI), FIB-4, AST/ALT ratio and BARD score is lower in the South Asian population compared to the Caucasian population [76]. Furthermore, the NAFLD fibrosis score has a lower sensitivity in patients of South Asian descent, since most of them had a lower BMI and were younger than Caucasian patients with a similar disease stage, and thus had a lower score (as BMI and age are components of the score). In contrast, another multicenter study of Southeast Asian (Malaysian and Chinese) and Caucasians showed that ethnicity did not affect the performance of the noninvasive tests performed [73].

Furthermore, studies from Japan and Hong Kong suggest that the BARD score is less accurate than what was reported initially in a Caucasian cohort $[65,77]$. Although the reason for this is unclear, one possible explanation is that BARD score includes BMI, and Asian patients have different fat distribution at the same BMI.

Although FibroMeter NAFLD is calculated using a proprietary formula, the components are simple clinical and laboratory parameters: age, body weight, platelets, AST, ALT, ferritin and fasting plasma glucose [78]. Ferritin is an acute phase protein that is increased in systemic inflammation or infection, and glucose may be affected by anti-diabetic treatment.

\section{Specific fibrosis biomarkers}

While the simple fibrosis scores are inexpensive, the components are not direct measurement of fibrogenesis or fibrinolysis and are therefore subject to various confounding effects. In contrast, there are also commercially available specific fibrosis biomarkers for the assessment of hepatic fibrosis in different liver diseases.

The Enhanced Liver Fibrosis (ELF) panel, consisting of procollagen III amino-terminal peptide (PIIINP), hyaluronic acid and tissue inhibitor of metalloproteinases 1 (TIMP1), has been validated in cross-sectional studies against liver biopsy and used alongside with liver biopsy in a number of phase 2 and 3 NASH trials [79]. In healthy people, the ELF score is higher in men and older subjects [80]. Besides, type III collagen is found in not only the liver but also many other organs together with type I collagen. Elevation of PIIINP level has been reported in bone fracture [81] and other fibrotic diseases such as burns [82], interstitial lung disease [83] and kidney disease [84]. TIMP1 is also increased in cancer [85] and inflammatory conditions such as psoriatic arthritis [86].

FibroTest comprises of gamma-glutamyl transpeptidase, total bilirubin, alpha-2-macroglobulin, apolipoprotein A1 and haptoglobin. Factors affecting GGT, haptoglobin and bilirubin levels have been described under SteatoTest and summarized in Table 3.
Pro-C3 measures the propeptide cleaved off from the intact collagen molecule and thus reflects type III collagen formation [87, 88]. It may also be increased in other fibrotic diseases, but data is scarce.

\section{Imaging studies}

\section{Ultrasound elastography}

Vibration-controlled transient elastography measures the velocity of shear wave in the liver parenchyma to estimate liver stiffness [89]. It has been extensively validated against liver histology [65, 90], and correlates with clinical outcomes in longitudinal studies [91]. Although validation studies are fewer, point-shear wave elastography and twodimensional shear wave elastography can be performed together with a regular ultrasound examination and therefore allow structural examination and hepatocellular carcinoma surveillance within the same session [92].

Pathologies that increase liver stiffness can lead to false positive diagnosis of advanced fibrosis or cirrhosis (Table 4). Grossly elevated liver stiffness has been reported in patients with acute viral hepatitis or acute exacerbation of chronic hepatitis B [93-95], though these conditions should have been excluded in the evaluation of NAFLD. Food intake also increases liver stiffness, probably through an increase in portal blood flow [96, 97]. Other wellcharacterized causes of spuriously high liver stiffness include congestive heart failure [98], biliary obstruction [99] and amyloidosis [100]. Solitary liver lesions such as hepatic cysts and hemangiomas have also been shown to increase liver stiffness measurement [101].

In addition, high body mass index and severe hepatic steatosis have been reported to increase the false positive rate of vibration-controlled transient elastography [102-104]. However, the effect of hepatic steatosis is not easily dissected from that of obesity, and the association between hepatic steatosis and high liver stiffness has not been consistently observed in other studies [65]. Nonetheless, a recent study suggests that steatosis does not increase liver stiffness independent of fibrosis when the XL probe is used in obese patients [90].

\section{Magnetic resonance imaging}

Magnetic resonance elastography measures liver stiffness by a modified phase-contrast method to image the propagation of shear wave in the liver [105]. By head-to-head comparison, magnetic resonance elastography has higher applicability and accuracy than vibration-controlled transient elastography [106, 107]. Although not systematically studied, factors increasing liver stiffness described above should also affect the performance of magnetic resonance 
Table 4 Imaging studies of hepatic fibrosis and potential confounding factors

\begin{tabular}{|c|c|}
\hline Test & $\begin{array}{l}\text { Potential } \\
\text { confounding factors }\end{array}$ \\
\hline $\begin{array}{l}\text { Ultrasound elastography (vibration- } \\
\text { controlled transient elastography, point- } \\
\text { shear wave elastography, 2-dimensional } \\
\text { shear wave elastography) }\end{array}$ & $\begin{array}{l}\text { Food intake } \\
\text { Active hepatitis } \\
\text { Biliary obstruction } \\
\text { Congestive heart } \\
\text { failure } \\
\text { Amyloidosis } \\
\text { Obesity and/or } \\
\text { hepatic steatosis } \\
\text { Inability to hold } \\
\text { breath (COPD) }\end{array}$ \\
\hline Magnetic resonance elastography & $\begin{array}{l}\text { Active hepatitis } \\
\text { Biliary obstruction } \\
\text { Iron overload } \\
\text { Amyloidosis } \\
\text { Sarcoidosis } \\
\text { Sinusoidal } \\
\text { obstruction } \\
\text { syndrome }\end{array}$ \\
\hline
\end{tabular}

elastography. Isolated reports also suggest that liver stiffness measurement by magnetic resonance elastography is affected by iron overload, sarcoidosis and sinusoidal obstruction syndrome. We did not identify any study on the influence of food intake on liver stiffness measurement by magnetic resonance elastography, though radiologists usually advise patients to fast before MRI examinations.

Corrected T1 measurement by MRI correlates with necroinflammation and fibrosis [108, 109], and has been shown to predict liver-related events in a small study [110]. Data on the confounding factors of corrected T1 are limited.

\section{Conclusion}

Because a substantial number of people in the community have NAFLD and only a small fraction would eventually suffer from liver-related complications, non-invasive tests are preferred as the initial assessment. Many of the available tests have high negative predictive values to exclude advanced fibrosis and future liver-related events, yet falsepositive diagnoses of advanced disease are common. This review summarizes the known and potential confounding factors affecting the performance of non-invasive tests. Clinicians should interpret test results with caution when the tests are applied in patients with potential confounding factors.

Author contributions All authors contributed to the literature review and preparation of the manuscript. All authors read and approved the final manuscript.

\section{Compliance with ethical standards}

Conflict of interest Vincent Wong has served as a consultant or advisory board member for 3V-BIO, AbbVie, Allergan, Boehringer Ingelheim, Center for Outcomes Research in Liver diseases, Echosens, Gilead Sciences, Intercept, Novartis, Novo Nordisk, Perspectum Diagnostics, Pfizer and Terns. He has also served as a speaker for AbbVie, Bristol-Myers Squibb, Echosens and Gilead Sciences, and received a non-restrictive grant on NAFLD research from Gilead Sciences. The other authors declare no conflicts of interests.

Open Access This article is licensed under a Creative Commons Attribution 4.0 International License, which permits use, sharing, adaptation, distribution and reproduction in any medium or format, as long as you give appropriate credit to the original author(s) and the source, provide a link to the Creative Commons licence, and indicate if changes were made. The images or other third party material in this article are included in the article's Creative Commons licence, unless indicated otherwise in a credit line to the material. If material is not included in the article's Creative Commons licence and your intended use is not permitted by statutory regulation or exceeds the permitted use, you will need to obtain permission directly from the copyright holder. To view a copy of this licence, visit http://creativecommons. org/licenses/by/4.0/.

\section{References}

1. Younossi Z, Tacke F, Arrese M, et al. Global perspectives on nonalcoholic fatty liver disease and nonalcoholic steatohepatitis. Hepatology. 2019;69:2672-82.

2. Li J, Zou B, Yeo YH, et al. Prevalence, incidence, and outcome of non-alcoholic fatty liver disease in Asia, 1999-2019: a systematic review and meta-analysis. Lancet Gastroenterol Hepatol. 2019;4:389-98.

3. Cholankeril G, Ahmed A. Alcoholic liver disease replaces hepatitis $\mathrm{C}$ virus infection as the leading indication for liver transplantation in the United States. Clin Gastroenterol Hepatol. 2018;16:1356-8.

4. Younossi Z, Stepanova M, Ong JP, et al. Nonalcoholic steatohepatitis is the fastest growing cause of hepatocellular carcinoma in liver transplant candidates. Clin Gastroenterol Hepatol. 2019;17(748-755):e3.

5. Fan JG, Kim SU, Wong VW. New trends on obesity and NAFLD in Asia. J Hepatol. 2017;67:862-73.

6. Estes C, Anstee QM, Arias-Loste MT, et al. Modeling NAFLD disease burden in China, France, Germany, Italy, Japan, Spain, United Kingdom, and United States for the period 2016-2030. J Hepatol. 2018;69:896-904.

7. Wong VW, Chan WK, Chitturi S, et al. Asia-Pacific working party on non-alcoholic fatty liver disease guidelines 2017-part 1: definition, risk factors and assessment. J Gastroenterol Hepatol. 2018;33:70-85.

8. Wong VW, Wong GL, Choi PC, et al. Disease progression of non-alcoholic fatty liver disease: a prospective study with paired liver biopsies at 3 years. Gut. 2010;59:969-74. 
9. Singh S, Allen AM, Wang Z, et al. Fibrosis progression in nonalcoholic fatty liver vs nonalcoholic steatohepatitis: a systematic review and meta-analysis of paired-biopsy studies. Clin Gastroenterol Hepatol. 2015;13:643-54e1-9 (quiz e39-40).

10. Ekstedt M, Franzen LE, Mathiesen UL, et al. Long-term followup of patients with NAFLD and elevated liver enzymes. Hepatology. 2006;44:865-73.

11. Taylor RS, Taylor RJ, Bayliss S, et al. Association between fibrosis stage and outcomes of patients with non-alcoholic fatty liver disease: a systematic review and meta-analysis. Gastroenterology. 2020. https://doi.org/10.1053/j.gastro.2020.01.043.

12. Ratziu V, Charlotte F, Heurtier A, et al. Sampling variability of liver biopsy in nonalcoholic fatty liver disease. Gastroenterology. 2005;128:1898-906.

13. Vilar-Gomez E, Calzadilla-Bertot L, Wai-Sun Wong V, et al. Fibrosis severity as a determinant of cause-specific mortality in patients with advanced nonalcoholic fatty liver disease: a multinational cohort study. Gastroenterology. 2018;155(443-457): e17.

14. Wong VW, Adams LA, de Ledinghen V, et al. Noninvasive biomarkers in NAFLD and NASH-current progress and future promise. Nat Rev Gastroenterol Hepatol. 2018;15:461-78.

15. Castera L, Friedrich-Rust M, Loomba R. Noninvasive Assessment of liver disease in patients with nonalcoholic fatty liver disease. Gastroenterology. 2019;156(1264-1281):e4.

16. Chalasani N, Younossi Z, Lavine JE, et al. The diagnosis and management of nonalcoholic fatty liver disease: practice guidance from the American Association for the Study of Liver Diseases. Hepatology. 2018;67:328-57.

17. European Association for the Study of the Liver, European Association for the Study of Diabetes, European Association for the Study of Obesity. EASL-EASD-EASO clinical practice guidelines for the management of non-alcoholic fatty liver disease. J Hepatol. 2016;64:1388-402.

18. Younossi ZM, Stepanova M, Rafiq N, et al. Pathologic criteria for nonalcoholic steatohepatitis: interprotocol agreement and ability to predict liver-related mortality. Hepatology. 2011;53:1874-82.

19. Ekstedt M, Hagstrom H, Nasr P, et al. Fibrosis stage is the strongest predictor for disease-specific mortality in NAFLD after up to 33 years of follow-up. Hepatology. 2015;61:1547-54.

20. Liu K, Wong VW, Lau K, et al. Prognostic value of controlled attenuation parameter by transient elastography. Am J Gastroenterol. 2017;112:1812-23.

21. Jayakumar S, Middleton MS, Lawitz EJ, et al. Longitudinal correlations between MRE, MRI-PDFF, and liver histology in patients with non-alcoholic steatohepatitis: analysis of data from a phase II trial of selonsertib. J Hepatol. 2019;70:133-41.

22. Harrison SA, Bashir MR, Guy CD, et al. Resmetirom (MGL3196) for the treatment of non-alcoholic steatohepatitis: a multicentre, randomised, double-blind, placebo-controlled, phase 2 trial. Lancet. 2019;394:2012-24.

23. Loomba R, Neuschwander-Tetri BA, Sanyal A, et al. Multicenter validation of association between decline in MRI-PDFF and histologic response in nonalcoholic steatohepatitis. Hepatology. 2020. https://doi.org/10.1002/hep.31121.

24. Bril F, Barb D, Lomonaco R, et al. Change in hepatic fat content measured by MRI does not predict treatment-induced histological improvement of steatohepatitis. J Hepatol. 2020;72:401-10.

25. Wong VW. Predicting NASH response with liver fat: are we back to square one? J Hepatol. 2020;72:386-8.

26. Bedogni G, Bellentani S, Miglioli L, et al. The Fatty Liver Index: a simple and accurate predictor of hepatic steatosis in the general population. BMC Gastroenterol. 2006;6:33.
27. Ruhl CE, Everhart JE. Fatty liver indices in the multiethnic United States National Health and Nutrition Examination Survey. Aliment Pharmacol Ther. 2015;41:65-766.

28. Meffert PJ, Baumeister SE, Lerch MM, et al. Development, external validation, and comparative assessment of a new diagnostic score for hepatic steatosis. Am J Gastroenterol. 2014;109:1404-14.

29. Poynard T, Ratziu V, Naveau S, et al. The diagnostic value of biomarkers (SteatoTest) for the prediction of liver steatosis. Comp Hepatol. 2005;4:10.

30. Yip TC, Ma AJ, Wong VW, et al. Laboratory parameter-based machine learning model for excluding non-alcoholic fatty liver disease (NAFLD) in the general population. Aliment Pharmacol Ther. 2017;46:447-56.

31. McHenry S, Park Y, Browning JD, et al. Dallas steatosis index identifies patients with nonalcoholic fatty liver disease. Clin Gastroenterol Hepatol. 2020. https://doi.org/10.1016/j.cgh.2020. 01.020 .

32. Kabisch S, Bather S, Dambeck U, et al. Liver fat scores moderately reflect interventional changes in liver fat content by a low-fat diet but not by a low-carb diet. Nutrients. 2018. https:// doi.org/10.3390/nu1002015.

33. Conigrave KM, Degenhardt LJ, Whitfield JB, et al. CDT, GGT, and AST as markers of alcohol use: the WHO/ISBRA collaborative project. Alcohol Clin Exp Res. 2002;26:332-9.

34. Younossi ZM, Stepanova M, Ong J, et al. Effects of alcohol consumption and metabolic syndrome on mortality in patients with nonalcoholic and alcohol-related fatty liver disease. Clin Gastroenterol Hepatol. 2019;17(1625-1633):e1.

35. Lazo M, Hernaez R, Bonekamp S, et al. Non-alcoholic fatty liver disease and mortality among US adults: prospective cohort study. BMJ. 2011;343:d6891.

36. Saadeh S, Younossi ZM, Remer EM, et al. The utility of radiological imaging in nonalcoholic fatty liver disease. Gastroenterology. 2002;123:745-50.

37. Wang CC, Hsieh TC, Tseng TC, et al. Factors affecting the diagnostic accuracy of ultrasonography in assessing the severity of hepatic steatosis. J Formos Med Assoc. 2014;113:249-54.

38. De Lucia RE, Brage S, Sleigh A, et al. Validity of ultrasonography to assess hepatic steatosis compared to magnetic resonance spectroscopy as a criterion method in older adults. PLoS ONE. 2018;13:e0207923.

39. Bydder GM, Chapman RW, Harry D, et al. Computed tomography attenuation values in fatty liver. $\mathrm{J}$ Comput Tomogr. 1981;5:33-5.

40. Duman DG, Celikel C, Tuney D, et al. Computed tomography in nonalcoholic fatty liver disease: a useful tool for hepatosteatosis assessment? Dig Dis Sci. 2006;51:346-51.

41. Guyader D, Gandon Y, Deugnier Y, et al. Evaluation of computed tomography in the assessment of liver iron overload. A study of 46 cases of idiopathic hemochromatosis. Gastroenterology. 1989;97:737-43.

42. Karlas T, Petroff D, Sasso M, et al. Individual patient data metaanalysis of controlled attenuation parameter (CAP) technology for assessing steatosis. J Hepatol. 2017;66:1022-30.

43. Tuthill T, Carvajal-Gonzalez S, Amin N. Ultrasound-based controlled attenuation parameter (CAP) to detect longitudinal changes in liver fat when effect size is large - experience from a phase 2a, dose-ranging study assessming MRI-proton density fat fraction (PDFF) and CAP in parallel. Hepatology. 2019;70(Suppl 1):167A-8A.

44. Wong GL, Wong VW, Chim AM, et al. Factors associated with unreliable liver stiffness measurement and its failure with transient elastography in the Chinese population. J Gastroenterol Hepatol. 2011;26:300-5. 
45. Wong VW, Vergniol J, Wong GL, et al. Liver stiffness measurement using XL probe in patients with nonalcoholic fatty liver disease. Am J Gastroenterol. 2012;107:1862-71.

46. Chan WK, Nik Mustapha NR, Mahadeva S. Controlled attenuation parameter for the detection and quantification of hepatic steatosis in nonalcoholic fatty liver disease. J Gastroenterol Hepatol. 2014;29:1470-6.

47. Fujimori N, Tanaka N, Shibata S, et al. Controlled attenuation parameter is correlated with actual hepatic fat content in patients with non-alcoholic fatty liver disease with none-to-mild obesity and liver fibrosis. Hepatol Res. 2016;46:1019-27.

48. Jung KS, Kim BK, Kim SU, et al. Factors affecting the accuracy of controlled attenuation parameter (CAP) in assessing hepatic steatosis in patients with chronic liver disease. PLoS ONE. 2014;9:e98689.

49. Silva M, Costa Moreira P, Peixoto A, et al. Effect of meal ingestion on liver stiffness and controlled attenuation parameter. GE Port J Gastroenterol. 2019;26:99-104.

50. Wong VW, Petta S, Hiriart JB, et al. Validity criteria for the diagnosis of fatty liver by $\mathrm{M}$ probe-based controlled attenuation parameter. J Hepatol. 2017;67:577-84.

51. Caussy C, Alquiraish MH, Nguyen P, et al. Optimal threshold of controlled attenuation parameter with MRI-PDFF as the gold standard for the detection of hepatic steatosis. Hepatology. 2018;67:1348-59.

52. Caussy C, Brissot J, Singh S, et al. Prospective, same-day, direct comparison of CAP with the M vs the XL probe in patients with nonalcoholic fatty liver disease, using magnetic resonance imaging proton density fat fraction as the standard. Clin Gastroenterol Hepatol. 2019. https://doi.org/10.1016/j.cgh.2019.11. 060 .

53. Eddowes PJ, Sasso M, Allison M, et al. Accuracy of FibroScan controlled attenuation parameter and liver stiffness measurement in assessing steatosis and fibrosis in patients with nonalcoholic fatty liver disease. Gastroenterology. 2019;156:1717-30.

54. Idilman IS, Keskin O, Celik A, et al. A comparison of liver fat content as determined by magnetic resonance imaging-proton density fat fraction and MRS versus liver histology in non-alcoholic fatty liver disease. Acta Radiol. 2016;57:271-8.

55. McPherson S, Jonsson JR, Cowin GJ, et al. Magnetic resonance imaging and spectroscopy accurately estimate the severity of steatosis provided the stage of fibrosis is considered. J Hepatol. 2009;51:389-97.

56. Angulo P, Kleiner DE, Dam-Larsen S, et al. Liver fibrosis, but no other histologic features, is associated with long-term outcomes of patients with nonalcoholic fatty liver disease. Gastroenterology. 2015;149(389-97):e10.

57. Leung JC, Loong TC, Wei JL, et al. Histological severity and clinical outcomes of nonalcoholic fatty liver disease in nonobese patients. Hepatology. 2017;65:54-64.

58. Leung JC, Loong TC, Pang J, et al. Invasive and non-invasive assessment of portal hypertension. Hepatol Int. 2018;12:44-55.

59. Mittal S, El-Serag HB, Sada YH, et al. Hepatocellular carcinoma in the absence of cirrhosis in united states veterans is associated with nonalcoholic fatty liver disease. Clin Gastroenterol Hepatol. 2016;14(124-31):e1.

60. Ascha MS, Hanouneh IA, Lopez R, et al. The incidence and risk factors of hepatocellular carcinoma in patients with nonalcoholic steatohepatitis. Hepatology. 2010;51:1972-8.

61. Bhala N, Angulo P, van der Poorten D, et al. The natural history of nonalcoholic fatty liver disease with advanced fibrosis or cirrhosis: an international collaborative study. Hepatology. 2011;54:1208-16.

62. Kawamura Y, Arase Y, Ikeda K, et al. Large-scale long-term follow-up study of Japanese patients with non-alcoholic Fatty liver disease for the onset of hepatocellular carcinoma. Am J Gastroenterol. 2012;107:253-61.

63. Wong VW, Chitturi S, Wong GL, et al. Pathogenesis and novel treatment options for non-alcoholic steatohepatitis. Lancet Gastroenterol Hepatol. 2016;1:56-67.

64. Srivastava A, Gailer R, Tanwar S, et al. Prospective evaluation of a primary care referral pathway for patients with non-alcoholic fatty liver disease. J Hepatol. 2019;71:371-8.

65. Wong VW, Vergniol J, Wong GL, et al. Diagnosis of fibrosis and cirrhosis using liver stiffness measurement in nonalcoholic fatty liver disease. Hepatology. 2010;51:454-62.

66. Mahady SE, Macaskill P, Craig JC, et al. Diagnostic accuracy of noninvasive fibrosis scores in a population of individuals with a low prevalence of fibrosis. Clin Gastroenterol Hepatol. 2017;15(1453-1460):e1.

67. Unalp-Arida A, Ruhl CE. Liver fibrosis scores predict liver disease mortality in the United States population. Hepatology. 2017;66:84-95

68. Hagstrom H, Talback M, Andreasson A, et al. Ability of noninvasive scoring systems to identify individuals in the population at risk for severe liver disease. Gastroenterology. 2020;158:200-14.

69. McPherson S, Hardy T, Dufour JF, et al. Age as a confounding factor for the accurate non-invasive diagnosis of advanced NAFLD fibrosis. Am J Gastroenterol. 2017;112:740-51.

70. Sterling RK, Lissen E, Clumeck N, et al. Development of a simple noninvasive index to predict significant fibrosis in patients with HIV/HCV coinfection. Hepatology. 2006;43:1317-25.

71. Angulo P, Hui JM, Marchesini G, et al. The NAFLD fibrosis score: a noninvasive system that identifies liver fibrosis in patients with NAFLD. Hepatology. 2007;45:846-54.

72. Petta S, Wai-Sun Wong V, Bugianesi E, et al. Impact of obesity and alanine aminotransferase levels on the diagnostic accuracy for advanced liver fibrosis of noninvasive tools in patients with nonalcoholic fatty liver disease. Am J Gastroenterol. 2019;114:916-28.

73. Fu C, Wai JW, Nik Mustapha NR, et al. Performance of simple fibrosis scores in nonobese patients with nonalcoholic fatty liver disease. Clin Gastroenterol Hepatol. 2019. https://doi.org/10. 1016/j.cgh.2019.09.027.

74. Wong VW, Chu WC, Wong GL, et al. Prevalence of non-alcoholic fatty liver disease and advanced fibrosis in Hong Kong Chinese: a population study using proton-magnetic resonance spectroscopy and transient elastography. Gut. 2012;61:409-15.

75. Shaheen AA, Myers RP. Diagnostic accuracy of the aspartate aminotransferase-to-platelet ratio index for the prediction of hepatitis C-related fibrosis: a systematic review. Hepatology. 2007;46:912-21.

76. De Silva S, Li W, Kemos P, et al. Non-invasive markers of liver fibrosis in fatty liver disease are unreliable in people of South Asian descent. Frontline Gastroenterol. 2018;9:115-21.

77. Fujii H, Enomoto M, Fukushima W, et al. Applicability of BARD score to Japanese patients with NAFLD. Gut. 2009;58:1566-7 (author reply 1567).

78. Loong TC, Wei JL, Leung JC, et al. Application of the combined FibroMeter vibration-controlled transient elastography algorithm in Chinese patients with non-alcoholic fatty liver disease. J Gastroenterol Hepatol. 2017;32:1363-9.

79. Nobili V, Parkes J, Bottazzo G, et al. Performance of ELF serum markers in predicting fibrosis stage in pediatric non-alcoholic fatty liver disease. Gastroenterology. 2009;136:160-7.

80. Lichtinghagen R, Pietsch D, Bantel H, et al. The enhanced liver fibrosis (ELF) score: normal values, influence factors and proposed cut-off values. J Hepatol. 2013;59:236-42. 
81. Kurdy NM. Serology of abnormal fracture healing: the role of PIIINP, PICP, and BsALP. J Orthop Trauma. 2000;14:48-53.

82. Ulrich D, Noah EM, Burchardt ER, et al. Serum concentration of amino-terminal propeptide of type III procollagen (PIIINP) as a prognostic marker for skin fibrosis after scar correction in burned patients. Burns. 2002;28:766-71.

83. Madahar P, Duprez DA, Podolanczuk AJ, et al. Collagen biomarkers and subclinical interstitial lung disease: the multiethnic study of atherosclerosis. Respir Med. 2018;140:108-14.

84. Heickendorff L, Frost L, Madsen JK, et al. Serum propeptides of type I and III procollagens in renal transplant recipients. A comparison of cyclosporine and azathioprine treatment. Nephron. 1994;67:203-8.

85. Ishida H, Murata N, Hayashi Y, et al. Serum levels of tissue inhibitor of metalloproteinases-1 (TIMP-1) in colorectal cancer patients. Surg Today. 2003;33:885-92.

86. Myers A, Lakey R, Cawston TE, et al. Serum MMP-1 and TIMP-1 levels are increased in patients with psoriatic arthritis and their siblings. Rheumatology (Oxford). 2004;43:272-6.

87. Nielsen MJ, Nedergaard AF, Sun $S$, et al. The neo-epitope specific PRO-C3 ELISA measures true formation of type III collagen associated with liver and muscle parameters. Am J Transl Res. 2013;5:303-15.

88. Daniels SJ, Leeming DJ, Eslam M, et al. ADAPT: an algorithm incorporating PRO-C3 accurately identifies patients with NAFLD and advanced fibrosis. Hepatology. 2019;69:1075-86.

89. Zhang X, Wong GL, Wong VW. Application of transient elastography in nonalcoholic fatty liver disease. Clin Mol Hepatol. 2020;26:128-41.

90. Wong VW, Irles M, Wong GL, et al. Unified interpretation of liver stiffness measurement by $\mathrm{M}$ and XL probes in non-alcoholic fatty liver disease. Gut. 2019;68:2057-64.

91. Shili-Masmoudi S, Wong GL, Hiriart JB, et al. Liver stiffness measurement predicts long-term survival and complications in non-alcoholic fatty liver disease. Liver Int. 2020;40:581-9.

92. Cassinotto C, Boursier J, de Ledinghen V, et al. Liver stiffness in nonalcoholic fatty liver disease: a comparison of supersonic shear imaging, FibroScan, and ARFI with liver biopsy. Hepatology. 2016;63:1817-27.

93. Arena U, Vizzutti F, Corti G, et al. Acute viral hepatitis increases liver stiffness values measured by transient elastography. Hepatology. 2008;47:380-4.

94. Sagir A, Erhardt A, Schmitt M, et al. Transient elastography is unreliable for detection of cirrhosis in patients with acute liver damage. Hepatology. 2008;47:592-5.

95. Wong GL, Wong VW, Choi PC, et al. Increased liver stiffness measurement by transient elastography in severe acute exacerbation of chronic hepatitis B. J Gastroenterol Hepatol. 2009;24:1002-7.

96. Mederacke I, Wursthorn K, Kirschner J, et al. Food intake increases liver stiffness in patients with chronic or resolved hepatitis C virus infection. Liver Int. 2009;29:1500-6.

97. Popescu A, Bota S, Sporea I, et al. The influence of food intake on liver stiffness values assessed by acoustic radiation force impulse elastography-preliminary results. Ultrasound Med Biol. 2013;39:579-84.

98. Millonig G, Friedrich S, Adolf S, et al. Liver stiffness is directly influenced by central venous pressure. J Hepatol. 2010;52:206-10.

99. Millonig G, Reimann FM, Friedrich S, et al. Extrahepatic cholestasis increases liver stiffness (FibroScan) irrespective of fibrosis. Hepatology. 2008;48:1718-23.

100. Loustaud-Ratti VR, Cypierre A, Rousseau A, et al. Non-invasive detection of hepatic amyloidosis: FibroScan, a new tool. Amyloid. 2011;18:19-24.

101. Wong GL, Kwok R, Wong VW. Huge adrenal hemangioma: a rare cause of deceivingly high liver stiffness measurement by transient elastography. Clin Gastroenterol Hepatol. 2015;13:e37-e3838.

102. Wong GL, Chan HL, Choi PC, et al. Association between anthropometric parameters and measurements of liver stiffness by transient elastography. Clin Gastroenterol Hepatol. 2013;11(295-302):e1-3.

103. Petta S, Maida M, Macaluso FS, et al. The severity of steatosis influences liver stiffness measurement in patients with nonalcoholic fatty liver disease. Hepatology. 2015;62:1101-10.

104. Petta S, Wong VW, Camma C, et al. Improved noninvasive prediction of liver fibrosis by liver stiffness measurement in patients with nonalcoholic fatty liver disease accounting for controlled attenuation parameter values. Hepatology. 2017;65:1145-55.

105. Dulai PS, Sirlin CB, Loomba R. MRI and MRE for non-invasive quantitative assessment of hepatic steatosis and fibrosis in NAFLD and NASH: Clinical trials to clinical practice. J Hepatol. 2016;65:1006-16.

106. Imajo K, Kessoku $\mathrm{T}$, Honda $\mathrm{Y}$, et al. Magnetic resonance imaging more accurately classifies steatosis and fibrosis in patients with nonalcoholic fatty liver disease than transient elastography. Gastroenterology. 2016;150(626-637):e7.

107. Park CC, Nguyen P, Hernandez C, et al. Magnetic resonance elastography vs transient elastography in detection of fibrosis and noninvasive measurement of steatosis in patients with biopsy-proven nonalcoholic fatty liver disease. Gastroenterology. 2017;152(598-607):e2.

108. Banerjee R, Pavlides M, Tunnicliffe EM, et al. Multiparametric magnetic resonance for the non-invasive diagnosis of liver disease. J Hepatol. 2014;60:69-77.

109. Pavlides M, Banerjee R, Tunnicliffe EM, et al. Multiparametric magnetic resonance imaging for the assessment of non-alcoholic fatty liver disease severity. Liver Int. 2017;37:1065-73.

110. Pavlides M, Banerjee R, Sellwood J, et al. Multiparametric magnetic resonance imaging predicts clinical outcomes in patients with chronic liver disease. J Hepatol. 2016;64:308-15.

Publisher's Note Springer Nature remains neutral with regard to jurisdictional claims in published maps and institutional affiliations. 